\title{
DE LOS DERECHOS HUMANOS AL DERECHO AL ABORTO*
}

\author{
Alejandra Zúñiga Fajuri \\ Universidad de Valparaíso \\ Universidad Diego Portales
}

RESUMEN: Ninguna otra persona, en ninguna situación, es obligada a realizar el acto supererogatorio que se exige a la mujer embarazada. Aun cuando una adecuada aplicación de la teoría general de los derechos humanos permite reconocer el derecho al aborto durante los dos primeros trimestres del embarazo sobre la base de que los derechos sólo pueden restringirse por mor de los propios derechos. En esa línea, se intenta responder a quienes sostienen que el problema del aborto no puede resolverse pues no existe forma de identificar un momento exacto a lo largo del desarrollo del embrión que permita diferenciar entre un aborto legítimo y uno ilegítimo. Se defiende que existen potentes argumentos morales para definir una postura que reduzca la incertidumbre y permita fundamentar reformas legislativas de despenalización.

Palabras claves: Derechos humanos, aborto, plazos.

\section{From Human Rights to Abortion Rights}

ABSTRACT: No one, in no other situation, is compelled to perform the supererogatory acts required of pregnant women. This article intends to show that an adequate reading of general human rights theory should include abortion rights through the first two trimesters of pregnancy, noting that basic liberties can only be limited for the sake of liberty itself. It also intends to respond to those who claim that the abortion issue cannot be resolved, since the exact point in embryonic development that separates legitimate and illegitimate abortion cannot be determined. Potent moral arguments exist for an approach capable of reducing uncertainty and establishing a basis for legal reforms.

Keywords: Human rigths, abortion, deadlines.

* Fecha de recepción: 15 de enero de 2013. Fecha de aceptación: 20 de septiembre de 2013.

Este artículo forma parte del Proyecto Fondecyt núm. 1120022. 


\section{INTRODUCCIÓN}

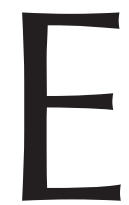

n general la teoría de los derechos humanos — por la que se ha vertido un mar de tinta - no suele utilizarse para defender el derecho al aborto. Ello parece un error que se funda, probablemente, en la muy extendida (y a veces velada) convicción de que la mujer embarazada ya no es, por esa sola condición, titular legítima de derechos humanos puesto que, debido a su estado, debe ceder e incluso renunciar a ellos a favor de un «otro». Esta creencia, que de alguna manera sustenta la mayoría de las legislaciones sobre el aborto en el mundo, pone en cuestión la completa «humanidad» y dignidad de la mujer embarazada, olvidando que, a la luz de una de las formulaciones del imperativo categórico kantiano, nunca debiéramos usarla como medio para satisfacer los fines de otros.

En las líneas que siguen quisiera evidenciar cómo una adecuada aplicación de la teoría general de los derechos humanos nos permite reconocer el derecho al aborto durante los dos primeros trimestres del embarazo teniendo presente que - como sostenía J. RAWLS- los derechos sólo pueden restringirse por mor de los propios derechos ${ }^{1}$. Junto con ello intentaré responder a quienes sostienen que el problema del aborto no puede resolverse pues no existe forma de identificar un momento exacto a lo largo del desarrollo del embrión que permita diferenciar entre un aborto legítimo y uno ilegítimo. Creo que existen potentes argumentos morales para definir una postura que reduzca la incertidumbre y permita fundamentar reformas legislativas de despenalización que, dejando atrás las indicaciones, se centren en la importancia moral de los plazos.

\section{LA MAYOR DESIGUALDAD DEL MUNDO EN MATERIA SANITARIA}

La Organización Mundial de la Salud, el Comité de Derechos Humanos de la ONU, el Comité contra la Tortura, el Comité de Derechos Económicos, Sociales y Culturales, el Comité para la Eliminación de la Discriminación contra la Mujer, la Comisión Interamericana de Derechos Humanos, Amnistía Internacional, Human Rights Watch, entre otros, han condenado unánimemente la vigencia en Chile, Nicaragua y El Salvador de normas que penalizan el aborto en todos los casos, esto es, aun cuando la vida o salud de la madre corren peligro o cuando el embarazo es producto de una violación. Para el Comité contra la Tortura, la aplicación de esas normas constituye un acto de tortura que viola los derechos humanos básicos de las mujeres²

Las muertes maternas están estancadas desde hace 20 años, con más de 500.000 al año. La mortalidad materna es la principal causa de muerte entre mujeres en edad fértil en los países en desarrollo y la inmensa mayoría de estas muertes son evitables, lo que

1 J. Rawls, A Theory of justice, Harvard University Press. 1971, 204.

2 El Comité contra la Tortura ha dejado claro que la política de Chile de retrasar el tratamiento para forzar confesiones de las mujeres que buscan «tratamiento para salvar la vida en hospitales públicos después de abortos ilegales, negándoles tratamientos confidenciales o usando sus declaraciones contra ellas en un procedimiento constituye una contravención de la Convención contra la Tortura», CCT, Observaciones concluyentes, Chile, U.N.Doc. CAT/C/CR/32/5, 14 de junio de 2004. 
evidencia que se trata de «la mayor desigualdad del mundo en materia sanitaria» ${ }^{3}$. Las causas de estas muertes siguen siendo las mismas: hemorragias postparto, infecciones, parto prolongado y, como sabemos, los abortos clandestinos, que constituyen un 30 por 100 de la tasa anual de mortalidad materna. Ello resulta especialmente alarmante si se tiene en cuenta que se trata de uno de los factores más fáciles de eliminar si se promueve la planificación familiar, se despenaliza la interrupción voluntaria de la gestación y se democratiza el acceso al cuidado sanitario. Cerca de 200 mujeres mueren al día en todo el mundo al someterse a un aborto sin las mínimas condiciones de higiene ${ }^{4}$. La tendencia a la baja en el número de hijos no ha evitado que aún boy cerca del 50 por 100 de los embarazos sean no deseados, por lo que cada año se practican 20 millones de abortos en condiciones insalubres, con métodos peligrosos o autoinducidos, lo que significa que este año unas $\mathbf{8 0 . 0 0 0}$ mujeres morirán a consecuencia de este tipo de abortos. Además, más de cinco millones ingresarán en un hospital, quedarán estériles o sufrirán alteraciones durante el resto de su vida ${ }^{5}$ (aproximadamente 800.000 latinoamericanas son hospitalizadas anualmente debido a estas complicaciones) ${ }^{6}$.

Sostener la ilegalidad del aborto es una forma sumamente costosa, en vidas humanas, de distribuir recursos médicos escasos. «La pregunta no es si estamos de acuerdo o no con el aborto porque, ya sea legal o no, las mujeres se practican abortos - como lo demuestran las estadísticas-. Por el contrario, la alternativa es escoger entre la vida y la muerte de estas mujeres. Actualmente, mantener las leyes penalizantes vigentes significa escoger la muerte» ${ }^{7}$. Por cierto, como política criminal la penalización del aborto ha demostrado ser extraordinariamente ineficaz. Hacer que el aborto sea ilegal no reduce el número de abortos pues, sólo en América del Sur, aproximadamente 30 de cada 1.000 mujeres (de entre 15 y 45 años) se hacen un aborto por año. En Holanda, donde el aborto es legal, la cifra es 8 de cada 1.000. Penalizarlo sólo discrimina a las mujeres sin recursos pues donde el aborto es legal, el riesgo de muerte es menor de 1 por cada 500.000 mujeres. Esto significa que un aborto legal es más seguro que ningún otro tipo de procedimiento médico y que tiene un menor riesgo de muerte que un tratamiento con penicilina.

Dar a luz es uno de los eventos más peligrosos en la vida de una mujer. En Europa una de cada 10.000 mujeres muere en el parto. Dar a luz es mucho más peligroso que un aborto seguro, de modo que no hay motivos aceptables para que una mujer de escasos recursos muera, enferme o quede infértil como resultado de un aborto clandestino. En Chile los abortos inseguros son la tercera causa de muerte materna y, al igual que las víctimas de las sanciones penales derivadas, son un peligro sólo para quienes no pueden financiarse, en el sistema sanitario privado, una interrupción del embarazo sin riegos de manera clandestina ${ }^{8}$.

\footnotetext{
3 UNICEF. State of the World's Children, Informe del año 2011.

${ }^{4}$ United Nations Population Fund. Making reproductive rights and sexual and reproductive health reproductive rights and sexual and reproductive health a reality for all. UNPF, mayo de 2008.

5 Organización Mundial de la Salud. Unsafe abortion: Global and regional estimates of incidence of unsafe abortion and associated mortality in 2000, 4. ${ }^{a}$ ed., Ginebra, OMS, 2004.

${ }^{6}$ Childbirth by Choice Trust, Abortion in Law, History and Religion, Toronto, 1995, 39.

7 De la BARREDA SOlÓRZANO, El delito de aborto, una careta de buena conciencia, México, Instituto Nacional de Estudios Criminales, 1991.

8 Perfil de Salud de Mujeres y Hombres en Chile 2003. Organización Panamericana de la Salud/Organización Mundial de la Salud, 2003.
} 
Además, es muy importante reconocer que la penalización del aborto supone obligar a las mujeres a elegir entre el aborto clandestino y la maternidad bajo coacción, es decir, la prohibición penal de abortar no se limita a prohibir un hacer, sino que obliga además a una opción de vida que es la maternidad. Pero, como sostiene FerRAJOLI, el derecho penal puede únicamente imponer un no hacer, prohibir comportamientos, y no imponer conductas u opciones de vida. «Con la prohibición del aborto y con la consiguiente constricción penal a convertirse en madres se impone a las mujeres no tanto y no sólo el no abortar, cuanto una conmoción vital de incalculable alcance. No sólo la gestación y el parto, sino la renuncia a proyectos de vida diversos, la obligación de educar y mantener a un hijo, en una palabra, la constricción a una especie de servidumbre»?

\section{ABORTO Y DERECHOS HUMANOS}

Se afirma que los derechos humanos, defendidos por la teoría y filosofía política desde, al menos, el siglo XVIII, son derechos subjetivos que reconocen a su titular prerrogativas que sólo pueden ser limitadas con el fin de proteger otros derechos humanos detentados por quienes pertenecen «a la clase de los seres humanos»o, lo que según veremos parece ser lo mismo, por personas humanas. Ello acarrea, entonces, al menos dos importantes consecuencias: primero, que los derechos humanos no pueden restringirse o anularse con el fin de salvaguardar intereses colectivos, utilitarios o consecuencialistas, ni tampoco valores como el de «la vida humana» en abstracto o «la vida humana potencial» sustentados por grupos religiosos o ideológicos, aún cuando ellos sean mayoritarios. En segundo lugar, implica que, para decidir sobre la legitimidad moral y legalidad del aborto, debemos ser capaces de identificar, en contraposición con los derechos humanos de las mujeres, un derecho del embrión o feto en tanto persona bumana $\mathrm{o}$, si esto no es posible, al menos como ente independiente con algún interés jurídicamente protegible (no como valor).

Una primera aproximación a la noción de «derechos humanos» requiere analizar las dos unidades semánticas que la componen. Por una parte, la palabra «derecho» —que admite al menos tres sentidos - se utiliza en este caso para aludir a alguna forma de facultad o potestad que le asiste a una persona; y, por otro lado, la palabra «humanos» se refiere a la única propiedad relevante para ser titular de estos derechos. Esta formulación, aparentemente simple, ya tiene dos grandes dificultades asociadas a cada una de las palabras escindidas: qué significa tener un derecho y qué significa «ser humano» ${ }^{10}$.

Prestemos atención a este último problema. La palabra «humanos» alude a que la única propiedad que ha de satisfacerse para ser titular de estos derechos es la de per-

9 L. FERRAJOLI, «La cuestión del embrión: entre el derecho y la moral», en Jueces para la democracia, información y debate, núm. 44, Madrid, 2002. Destacado agregado.

10 C. Nino, Ética y Derechos Humanos, Buenos Aires, Paidós, 1984, y del mismo autor, «Los Titulares de los Derechos Humanos: El Concepto de Persona Moral», en Filosofía del Lenguaje, de la Ciencia, de los Derechos Humanos y Problemas de su Enseñanza, Sociedad Filosófica Iberoamericana, Universidad Autónoma de México, 1987. También, L. VillaViCENCIO, «¿Derechos humanos para quienes? Reflexiones sobre algunas cuestiones embarazosas», en Revista de Derecho de la Universidad Austral de Chile, vol. XXI, núm. 2, 2008, 35-36. 
tenecer a la «clase de los seres humanos» de modo que los derechos humanos serían aquellos derechos morales de que gozan las personas sólo por el hecho de ser tales. Pero ¿̇ignifica esto que la única circunstancia fáctica relevante para la fundamentación de los derechos humanos es el hecho de ser de la «especie humana», biológicamente hablando? Caracterizar el concepto de humano en términos de rasgos orgánicos muy elementales, tales como la estructura del cromosoma celular, supone en principio que todos los seres humanos tendrían necesariamente un título igual a tales derechos. Con todo, recuerda NiNO, en este caso no se advierte de qué manera esos rasgos biológicos, que aparecen desvinculados del contenido moral de los derechos, pueden servir como único fundamento para concederlos. «Suponer que ello es así parece involucrar un burdo "especísmo" análogo a posiciones racistas» (además de plantean problemas respecto de las personas con síndrome de Down, cuyas células tienen un cromosoma de más) ${ }^{11}$. Tampoco debiéramos vulnerar el famoso axioma de Hume, que nos inhabilita lógicamente para deducir prescripciones - como el deber de conceder un derechode meras descripciones - como lo es la constatación de que se poseen determinadas características biológicas. En fin, como sostiene SINGER, la ciudadanía moral no es una cuestión de teoría biológica (ni de ningún tipo de teoría descriptiva), sino de la teoría moral en un sentido amplio ${ }^{12}$.

La otra alternativa es caracterizar el concepto de ser humano sobre la base de propiedades que se consideran como moralmente relevantes para su titularidad: esas propiedades — siguiendo a KANT — son la racionalidad y la capacidad de proponerse fines o, en palabras de RAWLS, la capacidad de tener un sentido de la justicia y un sentido del bien ${ }^{13}$. Ahora, dejando de lado que esta hipótesis nos obliga a admitir la conclusión algo antipática de que hay miembros de la especie humana que no pertenecen a la «clase» de los seres humanos, podemos centrarnos en la idea de que los derechos humanos serían aquellos derechos morales de que gozan todos los seres con capacidad para tener conciencia de su identidad como titular independiente de intereses y para ajustar su vida a sus propios juicios de valor. La clase de seres a la que alude esta caracterización de los derechos humanos estaría compuesta, entonces, por todas las personas morales, siendo un hecho contingente (no necesario) que esa clase esté constituida principalmente por seres «biológicamente» humanos.

Avancemos ahora hacia la caracterización de los derechos humanos en un sentido analítico ${ }^{14}$. En primer lugar se dice que los derechos humanos son intrínsecos, lo que quiere decir que su posesión no depende de ninguna otra propiedad que el hecho de «pertenecer a la clase de los seres humanos» en el sentido que hemos descrito más arriba y que, en adelante, resumiremos con el término «persona humana» (lo que significa que existirían, también, «personas no humanas»). A continuación se sostiene que los

11 NinO, Ética y derechos humanos, Paidós, 1984, 44. Tampoco debiéramos vulnerar el famoso axioma de Hume, que nos inhabilita lógicamente para deducir prescripciones - como el deber de conceder un derecho- de meras descripciones - como lo es la constatación de que se poseen determinadas características biológicas-.

12 Singer, Ética práctica, Cambridge University Press, 1995.

13 Rawls, A Theory of Justice, Oxford University Press, 1971.

14 Vid. P. DE LORA, Memorias y frontera, el desafío de los derechos bumanos, Madrid, Alianza, 2006; F. LAPORTA, «El concepto de derechos humanos», Doxa, núm. 4, 1987; C. PEÑA, «Sobre el Concepto y el Fundamento de los Derechos Humanos», en Cuadernos de Análisis Jurídico, núm. 27, Santiago, Universidad Diego Portales, 1993, y L. Villavicencio, La Constitución y los Derechos Humanos, Santiago, Conosur, 1998. 
derechos humanos son universales, pues se trata de derechos de los cuales son titulares todos quienes sean personas humanas, sin excepción. Son además igualitarios, lo que quiere decir que todos quienes pertenecen a la clase de los seres humanos poseen un título igual a tales derechos.

Los derechos humanos son prioritarios o absolutos, pues se trata de exigencias morales fuertes y esa fuerza descansa en que son la concreción de bienes de particular relevancia para las personas. Luego, cuando se sostiene que los derechos humanos son derechos absolutos lo que queremos decir es, precisamente, que se trata de requerimientos morales que al entrar en conflicto con otros requerimientos morales los desplazan y anulan, quedando ellos como la exigencia moral que hay que satisfacer en todo caso» ${ }^{15}$. En este sentido se afirma que los derechos humanos tienen un carácter «prima facie», en principio no pueden ser vulnerados y sólo pueden verse limitados por los derechos de otras personas. En la línea de la Declaración de los Derechos del Hombre y del Ciudadano de 1789: «La libertad consiste en poder hacer todo lo que no dañe a los demás. Así, el ejercicio de los derechos naturales de cada hombre no tiene más límites que los que aseguran a los demás miembros de la sociedad el goce de estos mismos derechos. Estos límites sólo pueden ser determinados por la ley». Lo importante, para una teoría ética basada en los derechos humanos, es determinar las razones por las que podríamos, en esos supuestos, sacrificar los derechos; «especificar las circunstancias que nos permitan acabar con los bienes más importantes de la persona» ${ }^{16}$.

Otra importante característica es que se trata de derechos individualizados y no agregativos. Esto es, ningún ente que no pertenezca a la clase de los seres humanos, individualmente considerado, puede detentar tales derechos. Por lo tanto, ni la mayoría, ni el Estado, ni el bien común o cualquier otra denominación similar, tienen derechos concurrentes que puedan justificar moralmente su violación o excepción y podemos incluir aquí, ni valores de tipo religioso o metafísico como el «sagrado valor de la vida humana» o el valor abstracto de «la vida humana en potencia». Por último, se trata de derechos contramayoritarios que se comportan como límite, umbral o «carta de triunfo» en contra de medidas fundadas en la consecución de objetivos sociales colectivos ${ }^{17}$. Si un derecho cediera - arguye NINO— cada vez que se demostrase que su ignorancia conduce a una situación socialmente valiosa, no sería un genuino derecho sino una concesión precaria que sólo se hace en vista del interés colectivo. Entonces, los derechos humanos son derechos fuertes en el sentido que no admiten restricciones justificadas en la obtención de objetivos sociales o comunes, aunque sean deseables de alcanzar ${ }^{18}$.

15 F. LAPORTA, «El concepto de derechos humanos», Doxa, 4, 1987, 39.

16 P. DE LORA, Memorias y frontera, el desafio de los derechos humanos, Madrid, Alianza, 2006, 120.

17 R. Dworkin, Los Derechos en Serio, Barcelona, Ariel, 1989, 58 a 162.

18 Si bien hay autores que sostienen que, además, los derechos humanos son inalienables o irrenunciables, la mayoría de los teóricos políticos rechazan este concepto por su carácter paternalista y, en cierto modo, autoritario, pues sostener la irrenunciabilidad de un derecho lo transformaría, por definición, en un «derecho-deber», lo que es un contrasentido que no se justifica moralmente. Por lo mismo, esta tesis — que cae en la contradicción derivada de suponer que los derechos humanos son irrenunciables hasta por sus propios titulares- puede superarse siguiendo a Laporta quien distingue entre la «titularidad» de los derechos y su «ejercicio». En general, la titularidad de los derechos humanos sería inalienable, pero su ejercicio puede ser voluntariamente limitado por el propio titular. Ibid., LAPORTA, 1987, 44. 
En conclusión, considerar «en serio» los derechos humanos de las mujeres, exige aceptar que se trata de derechos que sólo pueden ser limitados con el fin de proteger otros derechos humanos individualmente detentados por otra persona, de modo que resulta forzoso descartar como ilegítimos los fundamentos que distintas legislaciones y tribunales han esgrimido para justificar la penalización del aborto: la protección del «valor abstracto de la vida humana» ${ }^{19}$. En cambio, la única manera de limitar los derechos de las mujeres - compatible con el concepto y características que se han apuntado- requiere partir de los siguientes supuestos: primero, se precisa analizar si el feto posee las características que usualmente atribuimos a las personas, únicas titulares de derechos. Segundo, de no ser posible lo anterior, debemos analizar si es factible que, a partir de cierto momento de su desarrollo, el feto despliegue particularidades que ameriten que le atribuyamos derechos.

¿Significa lo anterior que la única manera de limitar legítimamente los derechos humanos de las mujeres en materia reproductiva sería aceptando que el feto es una persona? Para algunos ni siquiera así sería posible. El clásico argumento, desarrollado por J. J. Thomson, que defiende la idea de que, aun considerando al feto como persona, la madre tendría, en ciertas circunstancias, el legítimo derecho de abortar, es el siguiente: «Permítanme pedirles que se imaginen que una mañana despiertan en la cama de un hospital, conectados de alguna manera a un hombre inconsciente que se encuentra en la cama contigua. Le dicen que ese hombre es un violinista famoso que tiene una enfermedad renal y su única forma de sobrevivir es manteniendo su sistema circulatorio conectado al de otro individuo con el mismo grupo sanguíneo y usted es la única persona con la sangre adecuada. Así, una asociación de amantes de la música le ha secuestrado y llevado a cabo la operación de conexión. Como se encuentra en un hospital de buena reputación podría, si quisiera, solicitar a un médico que le desconectara del violinista, en cuyo caso él moriría irremediablemente. Por otra parte, si permanece conectado durante "sólo" nueve meses, el violinista se recuperaría y podría luego usted ser desconectado sin poner en peligro su vida» ${ }^{20}$.

La autora considera que si nos viéramos inmersos en esta situación inesperada, no estaríamos moralmente obligados a permitir que el violinista utilizara nuestros riñones durante nueve meses. Ayudar al violinista sería, claro, un acto muy generoso de nuestra parte, pero decir esto es bastante distinto de decir que haríamos mal si actuáramos de otra manera y nos desconectáramos. La conclusión, por tanto, es que, aún considerando que el violinista sea un ser humano inocente, con el mismo derecho a la vida que el de cualquiera, ello no significa que pueda utilizar el cuerpo de otra persona para sobrevivir. La idea es mostrar el paralelismo de este caso hipotético con algunos casos de embarazos no deseados. Por ejemplo, resulta evidente que una mujer que ha quedado embarazada como resultado de una violación se encontraría a sí misma, de un momento a otro, «conectada» a un feto del que no es, de manera alguna, más responsable que lo que lo sería de la vida del violinista.

19 Vid., por ejemplo, Tribunal Constitucional Español, sentencia 53/1985, de 11 de abril de 1985; Corte Constitucional Alemana, sentencia del 25 de febrero de 1975, 39 BVerfGE 1; Corte Constitucional de Colombia, sentencia C-133, de 1994.

20 J. J. Thomson, «Una defensa del aborto», en Debate sobre el aborto, cinco ensayos de filosofía moral, Madrid, Cátedra, 1992. 
Ahora, el ejemplo de THOMSON nos permite identificar y destacar de qué modo la regla de oro formulada por KANT a modo de imperativo moral curiosamente no parece a la mayoría de los filósofos morales susceptible de vulneración, salvo en el caso de la mujer embarazada. En efecto ¿existe alguna situación bajo la cual, con o sin responsabilidad de por medio, la legislación obligue a una persona a sacrificarse con el fin de salvar la vida de otros? ${ }^{21}$ Podemos empezar con el famoso caso de la bomba programada $\mathrm{o}$ «the ticking bomb case» que nos pide que imaginemos que un terrorista que acaba de ser capturado confiesa que ha puesto una bomba que estallará de modo inminente y matará a cientos o miles de personas. En tal escenario ¿debiéramos torturar al terrorista para que nos diga dónde ha colocado la bomba? La mayoría de los filósofos morales (salvo los utilitaristas) consideran que, aun en este caso, por medio de la aplicación del principio de dignidad derivado del imperativo de KANT, sacrificar la integridad de una persona para salvar a otras, sería inmoral. Con independencia de su responsabilidad en la creación de la situación que coloca su vida e indemnidad en oposición a las de otras personas, se defiende el derecho del terrorista a seguir siendo tratado como «persona con dignidad», lo que implica no consentir en utilizarle como medio para lograr un fin legítimo. ¿Por qué no se razona igual con la mujer embarazada? Aun cuando ella pudiera ser totalmente responsable de su embarazo (aunque, en verdad, siempre lo será, como máximo, en un 50 por 100), y aun cuando considerásemos que el embrión es una persona con derechos humanos, no debiéramos sacrificar su indemnidad física para salvar al embrión. No debiéramos tratarla como medio para obtener ningún fin, por muy legítimo que pueda parecer.

Veamos otro ejemplo. Imagine usted que va conduciendo un coche y que, por ir hablando por móvil, no alcanza a frenar en la luz roja y atropella a un niño. Suponga que ese niño ha sufrido, a consecuencia del accidente, una fuerte hemorragia que le hace necesitar con urgencia una transfusión de sangre y que usted - le ha dicho la doctora- es la única persona que hay en el pueblo (se trata de un lugar relativamente aislado) que posee el mismo tipo de sangre. Al momento llega un policía que le pide que le acompañe para iniciar el procedimiento de rigor y le comunica que hay varios testigos de los hechos que le culpan del accidente por lo que debe usted conseguir a la brevedad un abogado si quiere tener alguna oportunidad con su defensa. La doctora le ruega que se quede y «done» sangre, pero usted —asustado- decide que es mejor no demorar más su reunión con su abogado, por lo que, sin considerar la gravedad del niño, se despide y abandona el hospital. Luego de unas horas, le informan que el niño ha muerto por la hemorragia. ¿Ha violado usted la ley por no donar su sangre? Usted me dirá que, evidentemente, no pues toda donación es, por definición, voluntaria y la donación de sangre - así como de órganos - se considera que debe ser siempre libre, aun cuando de ello pueda depender la vida de una persona. Esto, de nuevo, se deduce del derecho a la integridad física y psíquica del donante, del derecho a la inviolabilidad de su cuerpo, de modo que no hay delito ni reproche legal.

Parece inevitable, de nuevo, preguntarse por qué ese derecho a la libertad e inviolabilidad del propio cuerpo, que las legislaciones de todo el mundo occidental reconocen sin excepción a las personas, se pone en cuestión solo cuando se trata de una mujer

${ }^{21}$ Sobre el problema de la responsabilidad en el embarazo, vid. A. Ruiz Miguel, El aborto: problemas constitucionales, Madrid, Centro de Estudios Constitucionales, 1990, 44 y ss. 
embarazada. ¿Por qué ella sí debe prestar su cuerpo a otro si no quiere terminar en prisión? Además, sabemos que una maternidad no deseada puede destruir la vida de una mujer al obligarla a dejar de estudiar o trabajar, enfrentarla a la propia familia, reducirla a la miseria o ponerla en situación de no ser capaz de proveer al mantenimiento de sí misma y de su propio hijo. La punición del aborto es el único caso en que se penaliza la omisión no ya de un simple acto - como en el caso, por lo demás bastante aislado, de la «omisión de socorro»- sino de una opción de vida: la que consiste en no querer convertirse en madre ${ }^{22}$. A diferencia de lo que sucede con las restantes prohibiciones penales, la prohibición del aborto equivale también a una obligación: la obligación de convertirse en madre, de llevar a término un embarazo, de alimentar y educar a un hijo etc., todo ello en contraste con el principio de igualdad, que supone tratar a las mujeres con igual consideración y respeto, tutelando su identidad. La penalización del aborto despoja a la mujer la autonomía sobre su propio cuerpo y la reduce a cosa o instrumento de procreación sometida a fines que no son suyos y violando el imperativo de KANT.

\section{EMBRIONES, FETOS Y PERSONAS}

Sin perjuicio de lo anterior, lo cierto es que existen serias dificultades para considerar al feto como perteneciente a la «clase de los seres humanos» en el sentido que hemos descrito más arriba, es decir, como persona moral. En esta línea, debemos acordar algún concepto de persona que sintetice las dos nociones que suelen superponerse, la de persona legal y la de persona moral. Sobre el concepto de persona legal no hay gran discusión pues tanto la legislación española, chilena como la comparada expresan que sólo quienes han nacido son, técnicamente, «personas» para los efectos de la titularidad de derechos subjetivos.

¿Sin embargo, es el feto una persona moral? El concepto de persona moral ha sido especialmente desarrollado por J. RAWLS en base a la teoría de KANT sobre el actuar autónomo, el actuar ético. Desde este punto de vista los requisitos para ser considerados persona son más estrictos que el solo hecho de haber nacido. Las personas morales, según vimos, son aquellas capaces de detentar dos virtudes morales: por una parte, un sentido de la justicia y, por la otra, una cierta concepción del bien. El primero exige la capacidad de entender, aplicar y actuar según la concepción pública de la justicia que caracteriza a los términos equitativos de la cooperación social. La segunda, la capacidad de adoptar una cierta concepción del bien, esto es, «una familia ordenada de fines y objetivos últimos que definen la concepción que tiene la persona de lo que tiene valor en la vida humana» ${ }^{23}$. Y concluye RAWLS: «sólo los que pueden hacer justicia tienen derecho a la justicia» ${ }^{24}$ de modo que no parece posible considerar al feto como persona moral puesto que ni siquiera un recién nacido o un discapacitado mental sería

${ }^{22}$ L. FerRAJOLI, 2002, op. cit. El derecho español dispone que se incurre en un delito de omisión del deber de socorro cuando no se ayuda a una persona que se encuentra desamparada y en peligro manifiesto y grave, sin que exista ningún riesgo ni para sí mismo ni para terceros. También se castiga con la misma pena la conducta de aquella persona que, aunque no puede prestar directamente socorro, no solicita la ayuda de un tercero (art. 95 del Código Penal).

23 J. RaWLs, La Justicia como equidad. Una reformulación, Barcelona, Paidós, 2002, 43.

24 J. RAWLS, A Theory of justice, Harvard University Press, 1971, 510. 
capaz de responder a la noción de persona desarrollada a partir del ideal kantiano de autonomía moral.

Lo anterior resulta de vital importancia para la regulación del aborto. Desde ya parece ineludible aceptar que, puesto que no hay «otra persona» — sea legal o moralque pueda oponer sus derechos a los de la mujer, no habría justificación alguna para limitar o excluir sus derechos humanos. Además, se trata de derechos prioritarios e individualizados, por lo que sólo pueden verse coartados, en caso de conflicto, por mor de los derechos de otras personas pues ningún ente o valor que no sea una «persona moral individualmente considerada» detenta tales derechos. Esto, sin embargo, no significa que no podamos encontrar argumentos que permitan regular e incluso restringir el derecho al aborto, pero debemos hacerlo demostrando cómo es posible identificar en el feto, individualmente considerado, y en atención a sus distintas etapas de desarrollo, ciertas características morales compartidas con las personas, que ameriten que le atribuyamos derechos por sí mismo. Se requiere identificar cuándo el propio feto adquiere un interés relevante digno de ser protegido y capaz de desplazar el derecho fundamental de la mujer a la autonomía reproductiva. Aquí hay dos caminos posibles, primero, atender a la capacidad del feto de sentir dolor o de ser consciente de sufrimiento y, segundo, prestar atención al momento de la viabilidad fetal, esto es, a la capacidad del feto de vivir fuera del útero materno.

Empecemos por el segundo argumento. El problema asociado a la tesis de la viabilidad —utilizada, como se sabe, por la Corte Suprema estadounidense para despenalizar el aborto ya en el año $1973^{25}$ - está en que debido al rápido desarrollo de la ciencia el plazo de la viabilidad — que hoy ronda en las 24 semanas de gestación — podría ir variando obligándonos a restringir cada vez más los derechos de las mujeres. Dicho de otra forma, el criterio de la viabilidad sería arbitrario pues su fijación dependería de un factor variable en el tiempo y en el espacio, como es el estado de la técnica en un determinado país ${ }^{26}$. Con todo, RUIZ Miguel ha sostenido que esta no es una objeción suficiente pues habría abundantes campos donde las variaciones en los avances técnicos hacen variar también la aplicación de los criterios valorativos sin convertirlos en arbitrarios: «la única crítica decisiva al criterio de la viabilidad es que la dependencia, por sí sola, no es una razón justificativa suficiente para disponer libremente de la vida de un ser que se reconoce diferente» ${ }^{27}$. Ahora, como se anotó más arriba, el hecho de que se trate de un ser diferente y viable no le hace titular de derechos humanos pues no poseería, en principio, las características necesarias para pertenecer a la «clase de los seres humanos».

Luego, parece preferible argumentar en torno a si es posible que el feto - aun no siendo persona moral— posee algún interés independiente jurídicamente protegible, sustentado teóricamente en la convicción de que no es lo mismo un aborto temprano que uno tardío, tesis que ha venido a validar las reformas legislativas de varios países en Europa ${ }^{28}$. En palabras de VALDÉS «las obligaciones morales que se tienen frente a una

25 Vid. Roe vs. Wade, 410 U.S. 113, 1973. Revisada en Planned Parenthood vs. Casey, 505 U.S. 833, 1992.

26 SINGER, 1995, op. cit. 1990.

27 A. Ruiz Miguel, El aborto: problemas constitucionales, Madrid, Centro de Estudios Constitucionales,

28 En el último tiempo se han reemplazado las «leyes de indicaciones» por las «leyes de plazo» como sistemas de regulación del aborto en Europa y, en particular, en España. El «sistema de indicaciones», que permite 
persona ya nacida no son las mismas que las que se tienen frente a un óvulo fecundado. Por ejemplo, a este último no lo podemos lastimar ya que carece de toda sensibilidad. Tampoco parece como algo cuyos deseos o intereses personales o planes de vida podamos contrariar, porque simplemente no posee ninguno $[. . .]^{29} \gg$. Los óvulos fecundados resultan ser distintos de las personas precisamente en aquellos aspectos que importan a la moralidad (dolor, deseos o intereses).

La ciencia ha probado que el desarrollo del ser humano es un proceso gradual. «El óvulo fecundado es una célula individual que, después de unos días, sigue siendo un diminuto conjunto de células sin ningún rasgo anatómico del ser en el que se convertirá posteriormente [...] hasta los 14 días después de la fertilización, ni siquiera podemos saber si el embrión va a ser uno o dos individuos» ${ }^{30}$ ¿Es verdad que no existiría ninguna línea divisoria moralmente significativa entre el óvulo fecundado y el niño? Como vimos, las sugeridas normalmente - el nacimiento, la viabilidad y el movimiento- no parecen pertinentes. Sí parece importante, en cambio, la capacidad del feto de sentir dolor o de ser consciente de sufrimiento. Por ello, autores como SinGER consideran que si el feto es capaz de sentir dolor entonces «tendría interés en no sentirlo y a ese interés se le debería dar igual consideración que a los intereses similares de cualquier otro ser» ${ }^{31}$. En la misma línea, para DwORKIN resulta muy difícil defender la idea que postula que el feto tiene intereses propios, en particular, un interés en no ser destruido desde el momento mismo de la fecundación ${ }^{32}$. Pero, en cambio, sí es posible atribuir interés al feto cuando éste es capaz de sentir dolor. «Infligir dolor al feto, que está dotado de un sistema nervioso suficientemente desarrollado para sentirlo, es también muy desfavorable a sus intereses. Pero un feto no puede ser consciente del dolor hasta el final del embarazo porque hasta entonces su cerebro no está lo suficientemente desarrollado» ${ }^{33}$.

Las últimas investigaciones médicas publicadas en diversas revistas científicas indican que los fetos sólo son capaces de sentir dolor a las 29 o 30 semanas, entre 6 y 7 meses de embarazo, puesto que las estructuras cerebrales donde se reconoce un estímulo desagradable, son las últimas que se forman durante la gestación. El dolor viaja por el sistema nervioso y en el feto lo último que se forma son las células más especializadas del cerebro, la corteza cerebral. «La percepción del dolor requiere el reconocimiento

el aborto en determinadas situaciones, parte del esquema regla-excepción: la regla es el castigo del aborto; la excepción, permitir el aborto en ciertos supuestos expresamente regulados. Las indicaciones más frecuentes son la terapéutica, la ética o criminológica, la eugenésica y la económico-social. El «sistema de los plazos» supone que el aborto es completamente libre hasta que se llega a un momento determinado de la gestación que suele fijarse en torno a las doce primeras semanas del embarazo (como ocurre en España). Hasta que se cumpla dicho plazo, la madre puede decidir con entera libertad sobre la continuación o interrupción del embarazo, con la sola condición de que sea realizada por un médico en un hospital o consultorio que garantice un aborto seguro y, a veces, se suma la exigencia de una consulta previa médico-social de los profesionales correspondientes. A partir del plazo que señala la ley el aborto puede ser lícito siempre que se den alguna de las indicaciones recién vistas, en ROMEO CASABONA, «El derecho y la bioética ante los límites de la vida bumana», Madrid, Centro de Estudios Ramón Areces, 1994.

29 M. VALDÉS, «El problema del aborto: tres enfoques», en Bioética y Derecho, fundamentos y problemas actuales, R. VÁsQUEZ (ed.), México, Fondo de Cultura Económica, 1999, 131 y ss.

30 SINGER, 1995, op. cit., 69.

31 Id., SINGER, 203.

32 R. Dworkin, El Dominio de la Vida, Barcelona, Ariel, 1994, 19.

33 Id., DwORKIN, 27. 
consciente o conciencia de un estímulo nocivo. Ni los reflejos de retirada, ni las respuestas hormonales de estrés para procedimientos invasivos prueban la existencia de dolor en el feto, ya que pueden ser provocadas por estímulos no dolorosos y producirse sin el procesamiento cortical consciente. La conciencia del feto ante estímulos nocivos requiere conexiones funcionales tálamo-corticales. Las fibras tálamo-corticales comienzan a aparecer entre las 23 a 30 semanas de gestación, mientras que la electroencefalografía indica que la capacidad de percepción del dolor funcional en los recién nacidos prematuros no existe, probablemente, antes de las 29 o 30 semanas» $^{34}$.

Así, por lo demás, ha argumentado el Colegio de Bioética de México durante las discusiones originadas a propósito de la despenalización del aborto en dicho país. «Los conocimientos científicos sobre el genoma, la fertilización, el desarrollo del embrión humano y la fisiología del embarazo indican que el embrión de 12 semanas no es un individuo biológico ni mucho menos una persona, porque: a) Carece de vida independiente, ya que es totalmente inviable fuera del útero; $b$ ) Si bien posee el genoma humano completo, considerar que por esto el embrión de 12 semanas es persona, obligaría a aceptar como persona a cualquier célula u órgano del organismo adulto, que también tienen el genoma completo. La extirpación de un órgano equivaldría entonces a matar a miles de millones de personas; $c$ ) A las 12 semanas el desarrollo del cerebro está apenas en sus etapas iniciales y no se ha desarrollado la corteza cerebral ni se han establecido las conexiones nerviosas hacia esa región que son indispensables para que puedan existir las sensaciones; $d$ ) Por lo anterior, el embrión de 12 semanas no es capaz de experimentar dolor ni ninguna otra percepción sensorial, y mucho menos de sufrir o de gozar» ${ }^{35}$.

Esta evidencia científica parece haber sido uno de los principales fundamentos de la mayoría de las legislaciones del mundo desarrollado que han transitado desde las leyes de indicaciones a las leyes de plazos, pues parece razonable y coherente con la teoría de los derechos humanos que he venido analizando que, si la restricción de derechos requiere ser justificada sobre la base del dualismo «persona-persona», las legislaciones que regulen el aborto debieran limitarlo sólo cuando sea posible reconocer en el feto mismo alguna de las características relevantes compartidas por las personas humanas: percepción y conciencia del dolor. Es por ello que el límite legal para realizar abortos, en la mayoría de los países de Europa, es de 12 semanas. El país donde el límite es mayor es Chipre (con 28 semanas, pero sólo en ciertas circunstancias). Le siguen con 24 semanas Finlandia, el Reino Unido y Holanda. El resto de los países oscila entre

34 S. J. Lee, H. J. P. Ralston, E. A. Drey, J. C. Partridge y M. A. Rosen, «Fetal Pain. A Systematic Multidisciplinary Review of the Evidence», Journal of the American Medical Association (JAMA), agosto 24/31, 2005, vol. 294, núm. 8: 947-954. Los resultados de este estudio vienen a corroborar las conclusiones de estudios realizados en las décadas de los 80 y 90 del pasado siglo. Vid. S. W. G. DERBYSHIRE y A. FUREDI, «Fetal pain is a misnomer», British Medical Journal, vol. 313:795, septiembre, 1996; X. GIANNAKOULOPOULOS, W. SEPULVEDA, P. KOURTIS, V. GLOVER y N. M. FISK, «Fetal plasma cortisol and (beta)-endorphin response to intrauterine needling», Lancet, 1994, 9 de julio, 344 (8915): 73-74; P. WALL, R. MELZACK y M. FitzGERALD, «Neurobiology of fetal and neonatal pain», en P. WALL y R. MELZACK (eds.), Textbook of pain, Edinburgh, Churchill Livingstone, 1994; M. FitZgerald, Fetal pain: an update of current scientific knowledge, London, DoH, 1995; L. MrZLJAK, H. B. M. UyLings, I. Kostovic y C. G. van EDEN, «Prenatal development of neurons in prefrontal cortex: a qualitative Golgi study», Journal of comparative neurology, 1988, vol. 271, 3:355-386.

35 Informe del Colegio de Bioética de México, en Revista Proceso. Semanario de información y análisis, núm. 1590, 22 de abril de 2007, 8. 
las 12 y 22 semanas. En la misma línea, en los Estados Unidos resulta inconstitucional prohibir el aborto durante los dos primeros trimestres de embarazo ${ }^{36}$.

\section{CONCLUSIÓN}

Una interpretación adecuada de los conflictos que emanan de las normas constitucionales que reconocen derechos a las personas - las mujeres - y las normas legales que determinan el estatuto del embrión, debiera ir en la línea de aquel principio kantiano que defiende que los individuos son fines, no medios que puedan ser sacrificados o usados, sin su consentimiento, para alcanzar otros fines, principio que ha tenido un importante reconocimiento por la Corte Constitucional de Colombia que ha distinguido dos posiciones posibles: 1) La que asume la vida como algo «sagrado» y 2) aquella que estima que es un bien valioso pero «no sagrado», pues las creencias religiosas o las convicciones metafísicas que fundamentan la sacralización son apenas una entre diversas opciones ${ }^{37}$. Para el constitucional, estos dilemas se deben resolver desde una perspectiva secular y pluralista, que respete la autonomía moral del individuo y las libertades y derechos que inspiran el ordenamiento jurídico, pues las demandas heroicas fundadas en creencias religiosas sólo pueden revestir el carácter de opción, aun cuando «una inmensa mayoría de la población las estime intangibles» ${ }^{38}$.

Se trata, como ya se adivinará, de lo que RAWLS denominaba el «uso público de la razón», es decir, la evitación en el debate público de aquellos argumentos propios de doctrinas morales, filosóficas o religiosa «comprehensivas», que demandan a las autoridades del Estado que justifiquen sus decisiones sobre la base de razones intersubjetivamente válidas, razones que todos los miembros de la comunidad política puedan aceptar ${ }^{39}$. Legislaciones como la de Chile, El Salvador y Nicaragua, donde se penaliza el aborto en todas las circunstancias, sustentan la completa preminencia de uno de los bienes jurídicos en juego y el consiguiente sacrificio absoluto de todos los derechos fundamentales de la mujer embarazada, desconociendo su dignidad y reduciéndola «a un mero receptáculo de la vida en gestación, carente de derechos o de intereses constitucionalmente relevantes que ameriten protección» ${ }^{40}$. La mujer no puede jurídicamente ser obligada a adoptar comportamientos heroicos y el legislador no puede desconocer que, como ser humano plenamente digno, no se la puede convertir en un simple instrumento de reproducción de la especie humana.

Quienes argumentan a favor de la penalización del aborto suelen hacerlo en base a la idea de que las mujeres, una vez que quedan embarazadas, pierden su condición de personas, en el sentido que lo ha entendido occidente a partir de las grandes revoluciones del siglo XVIII, es decir, individuos dotados de derecho a la libertad, dignidad e igualdad. No se puede dejar de reconocer que el reclamo de las mujeres con un embarazo no deseado es un reclamo asociado a una apelación más amplia por la igualdad de

\footnotetext{
36 Roevs. Wade, 410 U.S. 1131973.

37 Corte Constitucional de Colombia, Sentencia C-239/97.

38 Ibid., Sentencia C-239/97.

39 J. RAWLS, Justicia como equidad, Madrid, Tecnos, 1999, 132-133.

40 Sentencia C-355/06. Bogotá, D. C, 10 de mayo de 2006.
} 
trato. Después de todo ningún otro individuo en ninguna otra situación es obligado a realizar el acto supererogatorio al que son obligadas las mujeres embarazadas.

La teoría general de los derechos humanos demanda coherencia en su aplicación práctica al problema bioético del aborto de modo que resulta imprescindible que las legislaciones que regulen el aborto lo restrinjan solo cuando sea posible reconocer en el nasciturus alguna de las características relevantes compartidas por las personas morales, como por ejemplo, la percepción o conciencia del dolor. Como la evidencia científica de los últimos 30 años ha confirmado que esa característica, que ameritaría una consideración jurídica, solo aparece en la última etapa del embarazo, entonces las legislaciones restrictivas debieran, no sólo despenalizar el aborto en aquellos casos calificados por las organizaciones de derechos humanos como graves (peligro para la salud y vida de la madre y violación) sino que además proponer una ley que dé debida importancia a los plazos en materia de desarrollo intrauterino y consideración moral y que, finalmente, reconozca que las mujeres no pierden su derecho a la libertad y dignidad con el embarazo. 